\title{
perifèria
}

Número 18(2), diciembre 2013

http://revistes.uab.cat/periferia

\section{Nòmades: un proyecto de expresión social}

\author{
Maite Marín \\ Fotografías: Jordi R. Renom \\ Universitat Autònoma de Barcelona \\ "El Centre" Ateneu Democràtic i Progressista, Caldes de Montbui ${ }^{1}$
}

\section{Resumen}

El Cicle Nòmades es una propuesta nacida para reflexionar sobre los nuevos nomadismos en la era de la globalización desde una perspectiva local. Surgido al calor de "El Centre" Ateneu Democràtic i Progressista, en Caldes de Montbui, en los márgenes del área metropolitana de Barcelona, su vocación desde el inicio ha sido generar debates críticos e innovadores sobre temas complejos. Para ello ha invitado a colectivos y personas que han vivido, documentado, reflexionado o creado desde el arte alrededor de la experiencia de los desplazamientos forzados, las migraciones y los nomadismos actuales.

\begin{abstract}
The Nomad Cycle arose from a desire to understand new forms of nomadism in the age of globalization from a local perspective. The context was Caldes de Montbui, a town on the outer edge of the Barcelona metropolitan area, where a group of persons involved in a local Atheneum had already been organizing critical and innovative public discussions on a number of complex issues. For the Nomad Cycle they invited groups and individuals, who had experienced, documented, reflected on, or created art relating to contemporary migration, forced displacement, or other kinds of circulation of persons.
\end{abstract}

\section{Nómadas del siglo XXI}

A pesar de que constantemente se insiste en las ideas de desterritorialización y deslocalización, la geografía se ha vuelto cada vez más concreta: las fronteras se blindan a sí mismas, los mares se vuelven infranqueables, se levantan muros en el interior de las ciudades y anillos de contención en países que ejercen de guardaespaldas de una Europa cada vez más inaccesible.

\footnotetext{
${ }^{1}$ Enviar correspondencia a: marinandina@gmail.com
} 


\section{perifèria}

Número 18(2), diciembre 2013

http://revistes.uab.cat/periferia

Esa relación paradójica deviene el núcleo duro de la contradicción de nuestro tiempo: gente que deambula por las ciudades globales ${ }^{2}$ con absoluta libertad y su opuesto: personas relegadas y condenadas al otro lado de la(s) frontera(s). La libertad de movimiento ha acabado convirtiéndose en una mercancía escasa, distribuida de manera desigual y con la que se trafica. Las posibilidades de movilidad y nomadismo se han convertido en uno de los factores de estratificación más relevantes de nuestra época.

Zygmunt Bauman (2007) retrocede hasta los inicios del capitalismo para señalar que los países europeos siempre tuvieron la necesidad de "drenar" hacia fuera de sus fronteras las personas que el sistema no podía mantener. En ese sentido, las migraciones de los siglos XIX y XX hacia América y Asia habrían sido maneras de expulsar la población excedente para mantener el funcionamiento fluido del engranaje capitalista. Pero la necesidad de expansión de un sistema económico basado en el crecimiento incesante ha producido que ya no queden espacios en blanco que ocupar, ni márgenes donde lanzar los excedentes de población generados por las políticas económicas y los conflictos bélicos desde las últimas décadas del siglo pasado. Con la globalización las personas "sobrantes" se producen en todas partes. En las periferias y en el centro. En las antiguas colonias y en las antiguas metrópolis. En los países ricos y en los empobrecidos. Y si no hay espacios vacíos las personas se mueven hacia donde pueden. Ya no hay destinos fijos, sino temporales. Allá donde se abren intersticios las personas se desplazan.

\footnotetext{
2 Tomamos el concepto de ciudad global de Saskia Sassen: "Se trata de un espacio que está centrado en el lugar, en el sentido de que está inserto en determinados emplazamientos estratégicos, y al tiempo es transterritorial, porque conecta emplazamientos que no están geográficamente próximos y, sin embargo, están intensamente conectados entre sí. En la red mundial, no se produce solo la trasmigración del capital, sino también la de las personas, tanto las ricas (es decir, la nueva fuerza laboral profesional transnacional) como las pobres (es decir, la mayoría de los trabajadores migrantes), y es un espacio para la transmigración de las formas culturales o la reterritorialización de subculturas «locales». Una cuestión importante es la de si es también un espacio para una nueva política, que supere la de la cultura y la identidad, si bien es probable, al menos en parte, que quede comprendida en estas últimas." (Sassen 2007: 44).
} 


\section{perifèria}

Número 18(2), diciembre 2013

http://revistes.uab.cat/periferia

Todos esos procesos han dado lugar a una "contrageografía de la globalización" en palabras de Sassen (2003). Un mapa de circuitos alternativos globales por donde las personas se mueven para generar, en la medida de lo posible, ingresos y beneficios para su subsistencia. El empobrecimiento progresivo de países y regiones por el impacto de las políticas de ajuste ha supuesto el crecimiento de esos circuitos alternativos y un cada vez mayor número de personas, especialmente mujeres, en espacios transnacionales realizando viajes transfronterizos.

\section{El "Cicle Nòmades"3}

El "Cicle Nòmades" nació en noviembre del 2011 para reflexionar de una manera crítica justamente sobre los claroscuros que acompañan los desplazamientos en pleno vendaval de la globalización. A lo largo de su trayectoria se han engarzado acciones que lo han ido convirtiendo en un proceso abierto, basado en la intervención colaborativa entre las personas y los colectivos invitados a participar.

De esta forma, cada acción nómada se ha convertido en un viaje para lanzar miradas cruzadas a temas complejos: la desmemoria y las invisibilizaciones de género en exilios y migraciones recientes; las nuevas geografías del éxodo y la importancia del territorio; los desplazamientos forzados y las estrategias cotidianas para sobrevivir en los campos de refugiados; las grandes fisuras entre discursos (leyes y derechos) y prácticas. Tampoco se ha querido perder de vista la reflexión sobre la permanente necesidad de las personas de moverse, de viajar a la búsqueda de mundos utópicos, de trascender las geografías y el espacio por puro afán de conocimiento y placer.

El arte visual, la antropología, la pedagogía, el documental, las memorias "domésticas", el urbanismo, el fotoperiodismo, el derecho o la música han sido algunas de las disciplinas desde las que se ha generado el intercambio.

\footnotetext{
${ }^{3}$ Para acceder a la descripción de las propuestas y a las entrevistas con los y las participantes del "Cicle Nòmades": http://www.nomades.tk
} 


\section{perifèria}

\section{Número 18(2), diciembre 2013 \\ http://revistes.uab.cat/periferia}

El escenario donde se llevan a cabo las acciones es "El Centre" Ateneu Democràtic i Progressista" de Caldes de Montbui un espacio de autogestión cultural con más de 140 años de historia. Esta elección permite abordar los procesos globales teniendo en cuenta su impacto en los ámbitos locales. En los dos años de recorrido ha logrado convocar a un nutrido y fiel público -tanto local como llegado de otras zonas de la comarca y de la propia ciudad de Barcelona- dispuesto a escuchar, preguntar, debatir y hasta proponer temas o proyectos con vida propia.

De los diversos hilos argumentales que han atravesado el "Cicle Nòmades", reseguimos dos que han sido relevantes en varias sesiones.

\section{Sobre migraciones y exilios recientes: la invisibilidad de las "otras" Perú-Barcelona, 1985 -2011}

Desde 1985, empezaron a llegar a Barcelona mujeres solas, procedentes de distintos puntos del Perú. El conflicto entre Sendero Luminoso y el ejército, a la vez que una situación económica muy crítica, impulsó a un número indeterminado de ellas a salir de su país para buscar nuevas opciones de vida.

España era en aquel momento un país sin ningún marco legal para la inmigración pero donde empezaba a existir una incipiente demanda para el trabajo doméstico y el cuidado de las personas que atrajo a mujeres de distintos lugares del mundo. Las peruanas fueron, junto a las filipinas y las dominicanas, pioneras que llegaron a Barcelona a finales de la década de los 80 y transformaron la dirección migratoria de Cataluña, que pasó de ser emisora de emigración a receptora de inmigrantes.

Sin embargo, la extraordinaria aportación de estas mujeres ha quedado relegada en la historia reciente de nuestras ciudades y pueblos. Un grupo de activistas peruanas ${ }^{4}$ decidió revertir este silencio y a través de fotografías recogidas de álbumes personales y de un documental que se fue creando a partir de las entrevistas realizadas, volvieron la vista sobre esta historia, que es su propia historia.

\footnotetext{
${ }^{4}$ El grupo de mujeres forma parte de la Plataforma Q'atary Perú.
} 


\section{perifèria}

Número 18(2), diciembre 2013

http://revistes.uab.cat/periferia

Las fotografías recopiladas y mostradas en la exposición que inauguró el "Cicle Nòmades" cuentan de sus vidas cotidianas y de la ciudad de Barcelona en diferentes períodos: de su llegada e instalación en los primeros tiempos; de sus dificultades para la inserción laboral y de su cada vez más intensa participación política tanto en Cataluña como en Perú. En el recorrido fotográfico, a la par que se leen las transformaciones personales, se atestiguan los cambios que fue viviendo en los últimos años el paisaje de la ciudad con ellas como protagonistas.

Elizabeth Maldonado y Úrsula Santacruz lograron transmitir en la charla que presentó el acto cómo gestaron y llevaron a cabo el proceso de levantar una memoria de las que ellas mismas formaban parte.

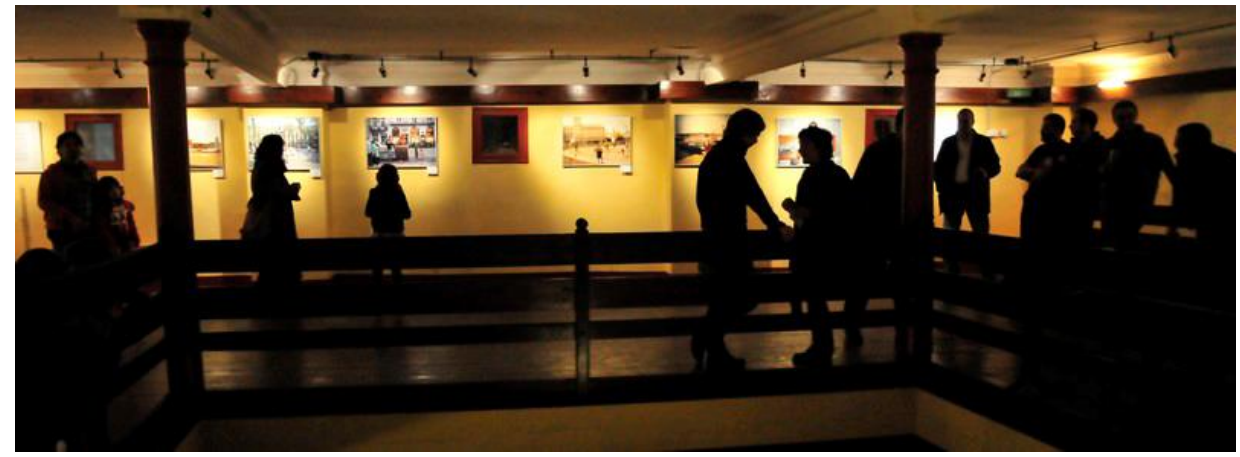

\section{Exilios silenciados}

Betty Puerto rememora, emocionada por la potencia del recuerdo y frente a un público sumido en un silencio espeso, su trayectoria como defensora de Derechos Humanos en Colombia, y su propia experiencia como mujer que, tras haber ayudado a salir del país a innumerables personas amenazadas desde su organización, se vio obligada a huir de su país y aterrizar como emigrante en Barcelona.

Han pasado años desde la llegada de las primeras mujeres colombianas defensoras de la vida a Barcelona pero Betty, desde su activismo en distintas entidades catalanas y colombianas, y a título personal, continúa reclamando su visibilidad en Cataluña y en el Estado Español, donde muchas de ellas han salido adelante sin ningún tipo de ayuda o reconocimiento, lejos de sus familias y transformadas en 


\section{perifèria}

Número 18(2), diciembre 2013

http://revistes.uab.cat/periferia

anónimas migrantes económicas. El testimonio de Betty encabalga tiempos y lugares, pero muestra la suma dolorosa de historias de personas perseguidas en sus países de origen y su vulnerabilidad extrema en estados como el español donde no se les reconocen sus derechos de asilo y refugio. El diálogo con Pepe Beunza, un referente del activismo político por la paz y los derechos humanos, y con las fotografías de Sofía Moro, retratos impactantes de defensores y defensoras de todo el mundo, enriqueció y acompañó el testimonio de Betty.
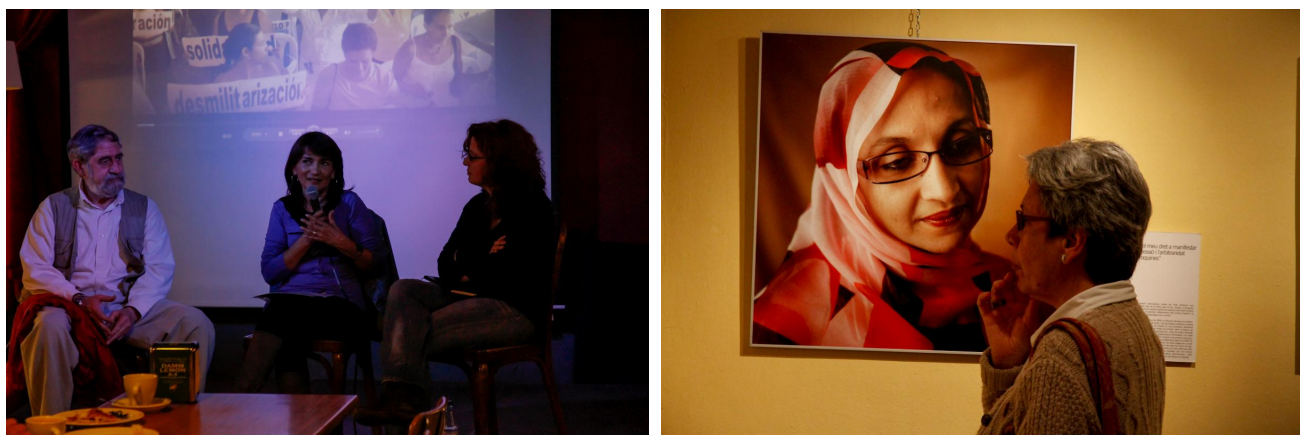

\section{Vidas y migraciones entretejidas}

En los últimos cinco años, en Cataluña, distintos grupos de mujeres han utilizado las arpilleras como método para elaborar, desde el tejido y la memoria, sus historias de vida. El origen de las arpilleras se remonta a la práctica de mujeres de Isla Negra, en Chile, que utilizando la ropa de los sacos y costales de harina "cosían" sus experiencias cotidianas de vida, tan poco visibles en la historia oficial. La técnica de las arpilleras sirvió para que años después otras mujeres chilenas explicasen al mundo en tejidos que salieron clandestinamente de Chile, la represión vivida por ellas y sus familias bajo el régimen de Pinochet. Desde entonces, las arpilleras y su técnica, comenzaron a viajar por el mundo y a ser reinterpretadas: Perú, Irlanda del Norte, Brasil, Cataluña...

Justamente por poner de relieve las experiencias de las mujeres, relegadas a menudo en su papel doméstico o encapsuladas en la vida familiar y reproductiva, las arpilleras son objetos muy valiosos para contar de las invisibilidades del género. Las experiencias migratorias (las protagonizadas por mujeres de distintos lugares de la Península que llegaron a Barcelona y su extrarradio en los años 50 y 60 , pero 


\section{perifèria}

Número 18(2), diciembre 2013

http://revistes.uab.cat/periferia

también las vividas en las últimas décadas por mujeres de otros países) son tema central de las arpilleras elaboradas en Cataluña.

Por este motivo, el "Cicle Nòmades" invitó a la Fundació Ateneu Sant Roc- que trabaja en este barrio nacido en Badalona durante los años 60- a reunir arpilleras alrededor del tema migratorio que mujeres de distintos orígenes habían tejido en talleres realizados en la propia Fundación.

La exposición y la charla quisieron poner en relación experiencias y arpilleras de mujeres que viven en un mismo territorio. Este diálogo mostró de una forma muy potente y visual intersecciones y puntos de fuga en las migraciones femeninas procedentes de Extremadura, Andalucía, el norte de África o Pakistán.
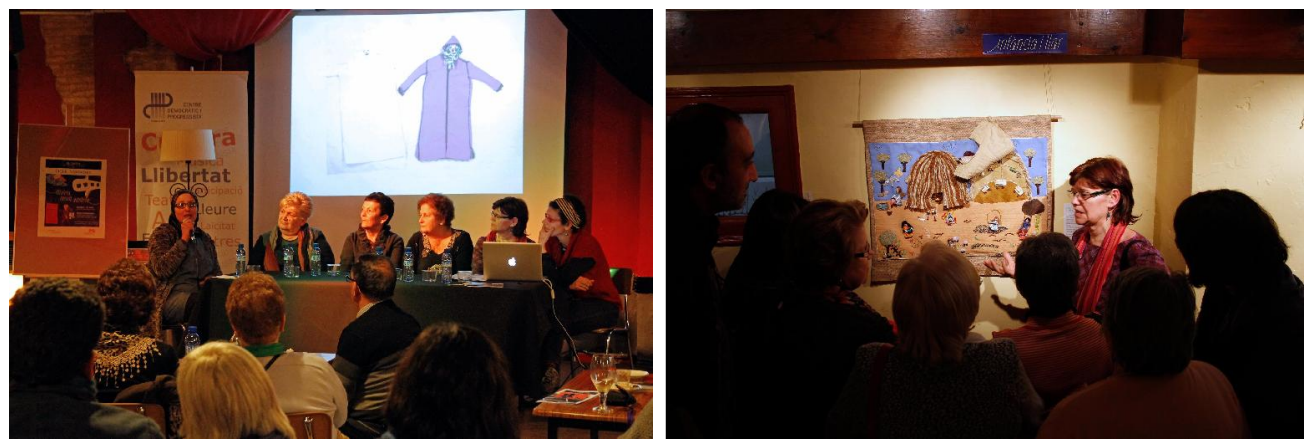

\section{Rastros en la geografía. De nomadismos y utopías}

Otro eje central de "Nòmades" ha girado entorno a las relaciones entre desplazamiento y territorio.

En la sesión "Viaje a la Utopía" el urbanista José Luis Oyón -en diálogo con la también urbanista Marta Serra- nos acercó a la figura de Elisée Reclus, geógrafo francés del siglo XIX y uno de los fundadores del anarquismo. Reclus hizo de los desplazamientos una experiencia continua de vida y fuente de sus reflexiones sobre la geografía, la libertad individual y la relación ciudad-naturaleza. En la sesión también se abordaron los nomadismos cotidianos y diarios entre centros urbanos y espacios periurbanos, así como la relación entre residencia, como forma de estabilidad y disfrute del lugar, y nomadismo, como sinónimo de búsqueda 


\section{perifèria}

Número 18(2), diciembre 2013

http://revistes.uab.cat/periferia

permanente de la utopía.

La sesión partió del trabajo que ambos urbanistas han realizado siguiendo el rastro de las más de 30 casas en las que Reclus vivió a lo largo de su vida y que lo llevaron a vivir y experimentar distintos tipos de nomadismos (Oyón y Serra, 2012).

El debate se alimentó con la intervención del colectivo Sitesize y de su exposición "iCatalunya termina aquí! iAquí empieza Murcia!". En las fotografías y textos se mostraban algunos escenarios de autogestión cultural obrera y se enfatizaban los espacios de libertad cercanos a la naturaleza a los que los obreros y obreras catalanes de principios del siglo XX se desplazaban los fines de semana en tiempo de ocio, desde las fábricas y los barrios para distanciarse de la alienación que las ciudades y el trabajo les implicaba.

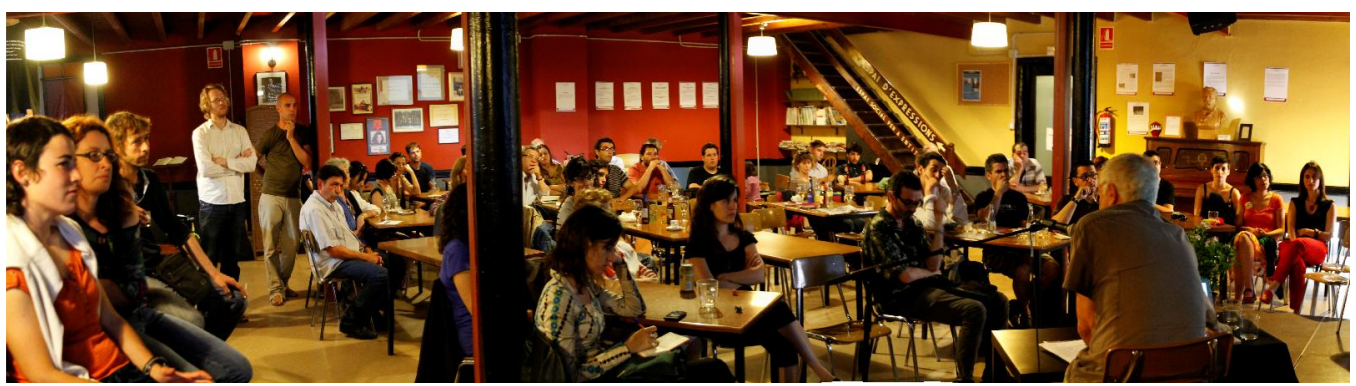

\section{8_Nakba: nómadas y extranjeros en Palestina}

En la sesión dedicada a Palestina se debatió entorno a la relación entre desplazamiento, identidad, memoria y territorio. El punto de partida fue la presentación del documental 48_Nakba. Nakba, que significa desgracia, es la manera que tienen los palestinos de significar lo que sucedió en 1948, cuando con la creación del Estado de Israel muchos de ellos fueron expulsados de sus territorios. Dos de los autores del documental, Sàgar Malé y Marta Ramoneda (de la Asociación de creación documental Mapasonor) y el artista visual Domènec que colaboró en la realización del film abordaron la condición nómada, de estar de paso, que se habrían impuesto los palestinos en los campos de refugiados habitados por 


\section{perifèria}

Número 18(2), diciembre 2013

http://revistes.uab.cat/periferia

más de 60 años como una estrategia de resistencia. La memoria vinculada a los lugares de origen de los que fueron expulsados, el tema central del documental, conforma una adscripción identitaria que se mantiene a través de las generaciones, a pesar de su destrucción y aniquilación intencionada por parte de Israel.

A través de imágenes y fotografías se incidió en la transformación urbanística de los campos de refugiados como lugares de vida a lo largo de 60 años - lugares en principio diseñados para ser de tránsito-; o en la creación de una memoria colectiva muy viva asociada a los lugares de origen que han sido destruidos y convertidos en "no lugares". Espacios que aún inexistentes, continúan amalgamando y articulando para los palestinos imaginarios de resistencias individuales y colectivas.

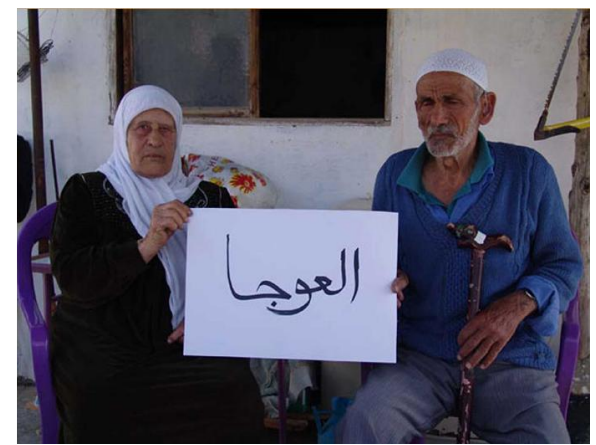

Fotograma del documental "48_Nakba"

\section{Geografías concretas: desplazamientos y rastros en el territorio}

"El 24 de febrero de 2004 dos excavadoras entraron en un descampado de Barcelona que había sido ocupado por unas sesenta familias gitanas. Durante varios días rompieron y levantaron el suelo de hormigón del solar con la intención de intimidar a los gitanos y finalmente expulsarlos de allí, dejando tras de si una superficie contorsionada, como una especie de muro horizontal, para proteger el solar y mantenerlo vacío. Este método de disuasión muestra el valor económico de la violencia y la destrucción aplicada al control del territorio. El suelo roto, las grietas, los pedazos de hormigón levantados como fragmentos de estelas mayas, dan testimonio, todavía hoy, de este desplazamiento." (Ribas, 2012) 


\section{perifèria}

Número 18(2), diciembre 2013

http://revistes.uab.cat/periferia

En su contundente trabajo fotográfico Nomads Xavier Ribas registra en una cuadrícula de 33 fotografías los rastros de la violencia institucional aplicada al territorio por la expulsión forzada de un grupo de gitanos rumanos que habían ocupado un solar abandonado de un barrio de Barcelona. Es un paisaje que abruma porque cuenta -desde la ausencia y el vacío después de cuatro años- lo que queda tras eliminar la presencia amenazante del otro. No se documenta ni la expulsión, ni la vida de las personas ni los recuerdos de los que ahí vivieron. Las fotografías muestran lo que queda de ese desplazamiento forzado de gitanos, un colectivo que incomoda porque pone en cuestión el orden social, las normas residenciales, la idea de propiedad hacia el territorio. Pero,

"el sujeto de este trabajo no es la representación de las familias gitanas sino la estrategia adoptada por los propietarios del solar para expulsarlas de él, de manera que lo que las imágenes quieren mostrar no son las huellas de la ocupación del solar sino el rastro de la violencia aplicada a la propiedad para expulsar a las familias gitanas y garantizar su control. Los pedazos rotos del suelo de hormigón son el indicio de ese desplazamiento". (Entrevista a Ribas, Navamuel, 2012).

Tomando como punto de partida los recorridos fotográficos y los interrogantes que plantea el trabajo de Xavier Ribas alrededor de las periferias y las expulsiones urbanas que tienen lugar en ellas -quizás las que pasan más desapercibidasseguimos indagando desde el "Cicle Nòmades" sobre territorios y desplazamientos. En las últimas década la especulación y los planes urbanísticos en Barcelona han promovido la expulsión y el desalojo de antiguos vecinos y minorías que han visto como sus casas han sido destruidas. En estos casos la planificación y la "ordenación" han provocado la desaparición de territorios de periferia en apariencia difusos, espacios potencialmente peligrosos como reductos de libertad.

Con Xavier Ribas conversaron e intercambiaron puntos de vista Kathrin GoldaPongratz, arquitecta, urbanista y fotógrafa que ha trabajado en Lima, Barcelona y Madrid; Emanuela Bové, arquitecta y miembro del colectivo Repensar Bonpastor y Núria Sánchez, antropóloga y fotógrafa, fundadora del grupo de antropología 


\section{perifèria}

Número 18(2), diciembre 2013

http://revistes.uab.cat/periferia

Perifèries Urbanes
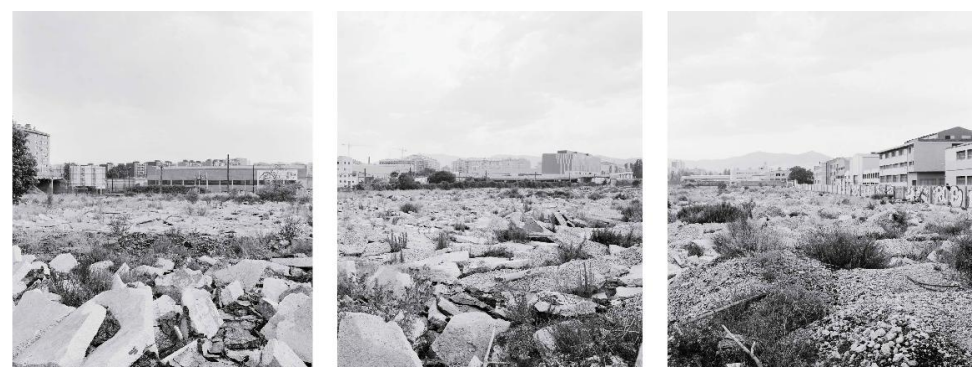

(c) Xavier Ribas - Nomads, 2008

\section{Escenarios futuros}

Haití, Túnez, Brasil, Afganistán... han sido otros tantos escenarios donde Nòmades se ha desplazado a través de la retina de Marta Ramoneda, del relato cinematográfico de Agustí Corominas, de la experiencia como activista y antropóloga de María Carballo o de la maestría de los músicos Efrén López, Miriam Encinas y Ciro Montanari. Campos de refugiados, tierras ocupadas, países devastados por guerras y conflictos, donde la vida, el arte y la capacidad de resistencia constituyen una lección de la que el "Cicle Nòmades" pretende ser una caja de resonancia.

En un futuro inmediato el objetivo es viajar a lugares de los que conocemos poco o nada de la mano de nuestros vecinos y vecinas de Caldes de Montbui que Ilegaron desde Mali, Pakistán o Ecuador en las últimas décadas. Historias de exilio y migraciones económico-políticas vividas por la gente de la propia comunidad y que tienen continuidad hasta nuestros días. Todo un reto para sumar lecturas que entroncan los movimientos poblacionales de ámbitos ( $y$ causas) globales con el pulso de la vida cotidiana en espacios locales. 


\section{perifèria}

Número 18(2), diciembre 2013

http://revistes.uab.cat/periferia

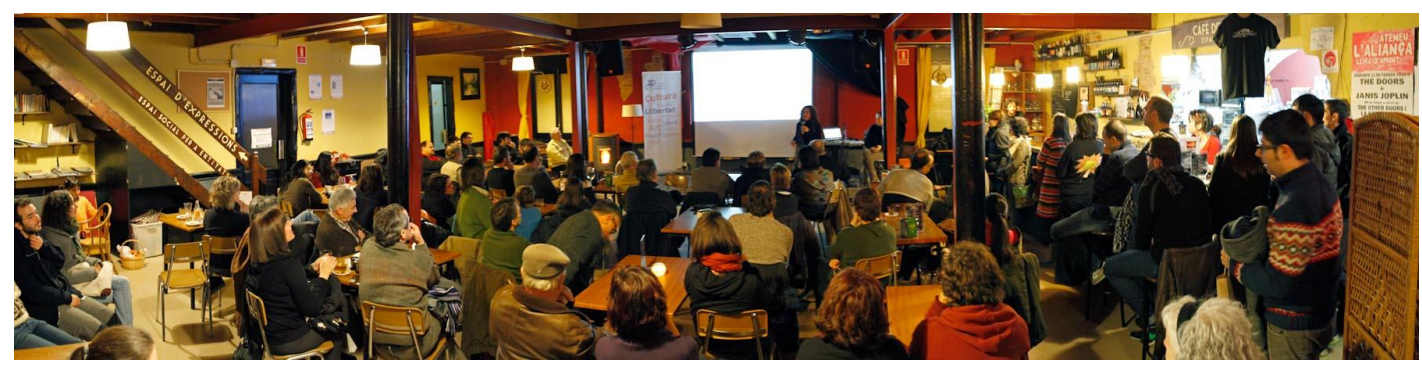

\section{Bibliografía}

Bauman, Zygmunt (2007). Confianza y temor en la ciudad. Vivir con extranjeros. Barcelona: Editorial Arcadia.

Navamuel, Francisco (2012). " "Entrevista a Xavier Ribas". Blog "A sangre". Disponible en: http://francisconavamuel. net/asangreblog/2012/07/05/geografiasconcretas-nomadas-de-xavier-ribas/ Consultado el 13 de noviembre de 2013.

Oyón, José Luis y Serra M. (2012). "Las casas de Reclus: hacia la fusión naturalezaciudad, 1870-1871". Scripta Nova. Revista electrónica de Geografía y Ciencias Sociales. Volumen XVI, núm. 451. Disponible en: http://www.ub.edu/geocrit/sn/sn421.htm. Consultado el 15 de noviembre de 2013.

Ribas, Xavier (2012). Nomads. BsideBooks.

Sassen, Saskia (2003). Contrageografías de la globalización. Género y ciudadanía en los circuitos transfronterizos. Madrid: Traficantes de Sueños.

Sassen, Saskia (2007). "La ciudad global: emplazamiento estratégico, nueva frontera". En: Laguillo, Manolo. Barcelona 1978 - 1997. Barcelona: Macba. pp. 3644. Disponible en http://www.macba.cat/PDFs/saskia_sassen_manolo_laguillo_cas.pdf Consultado 10 de noviembre de 2013 . 